\title{
Vedat Kamer interviews John Woods
}

\author{
Vedat $\operatorname{Kamer}^{1}{ }^{\mathbb{D}}$, John Woods ${ }^{2}$ (1)
}

Asst. Prof. Dr., Istanbul University, Faculty of Letters, Department of Philosophy, Istanbul, Turkey ${ }^{2}$ Prof. Dr., University of British Columbia, Vancouver - UBC, Department of Philosophy, Canada

ORCID: V.K. 0000-0001-9146-0923; J.W. 0000-0002-8852-9202

\section{Sorumlu yazar/Corresponding author:}

Vedat Kamer, Istanbul University, Faculty of Letters, Department of Philosophy, Istanbul, Turkey

E-mail/E-posta:vkamer@istanbul.edu.tr

Başvuru/Submitted: 20.11.2019 Kabul/Accepted: 27.12.2019

\section{Atıf/Citation:}

Kamer, Vedat and Woods, John. (2019). "Vedat Kamer interviews John Woods", Felsefe Arkivi- Archives of Philosophy, 51: $303-308$. https://doi.org/10.26650/arcp2019-5121

VK: It is a pleasure to welcome you to Felsefe Arkivi's Editorial Board Professor Woods, and thank you for agreeing to say something about the present state and future prospects of philosophy, and about what drew you to a philosophical career.

JW: I am honoured to be appointed to the Editorial Board, and I very much hope that I'll be able say something that might hold some interest for your readers.

VK: How did you decide to start studying logic?

JW: In my first undergraduate year at the University of Toronto (1954), Aristotle's syllogistic was lightly covered as part of the Introduction to Philosophy course of the Honours Programme. The textbook, by Angus Sinclair, was accurate as far as it went but contained nothing to convey how the syllogistic rules drive the engines of Aristotle's great foundational achievements in metalogic. In my second year in Toronto, I was exposed to symbolic logic in a textbook by Susanne K. Langer. I now know it to be an excellent introduction, but its algebraic approach 
puzzled me. When mathematicians prove theorems that advance algebra's cause, they are involved in some very serious thinking. They are reasoning with rigour and precision. But, as I then thought, there was little in those ways of thinking of an algebraic character. Even at that early stage, I found logic's historical link to truth-preserving human inference to be slipping away. My next exposure to logic was during my MA year in Toronto. We read Hilbert and Ackermann's Mathematical Logic, which I regarded as an excellent introduction to a relatively new part of mathematics. Later that year (1959) I was in Ann Arbor to begin my doctoral studies at the University of Michigan. Logic was a mandatory course for all first-year PhD students in philosophy and mathematics. The assigned text was Irving Copi's Symbolic Logic. But because of my standing in the Toronto course, I was not required to enrol, and didn't. The year following, I was in Richard Cartwright's class on the philosophy of logic. For the first time, I was able to see how the new mathematical methods of the $19^{\text {th }}$ century could be used to advantage in exploring matters of deep metaphysical importance, notably the mysteries of the transfinite and also (perhaps) the ontological challenges of necessity and possibility. But I had also come more firmly to the view that, in C. S. Peirce's words, "logic in the strict sense of the word has nothing to do with how you think." My last exposure to logic in Ann Arbor was in C. H. Langford's seminar on his and C. I. Lewis' famous proof in their co-authored Symbolic Logic (1932). The proof seeks to establish the truth of the ex falso quodlibet thesis, according to which any contradiction logically implies each and every sentence of the language within which the contradiction is expressed. Professor Langford had been seriously disabled by a stroke and, of necessity, his seminar was more of a graduate student discussion-session than a highly disciplined course. But it set my own logical compass. Although most of my fellow students found the proof to be faulty, I was wholly convinced by it. In 1962, I was appointed to the Toronto philosophy department, where I started my dissertation on Entailment and the Paradoxes of Strict Implication and completed it in 1965.

\section{VK: What was your favourite subject when you started studying philosophy?}

JW: I arrived at the University of Toronto as a seventeen year old freshman who intended to do an Honours Degree in political science. I would then enroll in Law School and, in the fullness of time, would join my father in the practice of law in my hometown, Barrie, Ontario. All that had changed before the Thanksgiving weekend (which, in Canada, falls on the second Monday of October). Home for the weekend, I announced that thenceforth I would seek a career in philosophy. "What a fool I have for a son!", was my mother's less than delighted response. My father said nothing, but I could see in his eyes that I had broken his heart. The cause of my reversal was twofold. In my last year of High School, our history teacher, the estimable William Fisher, would invite us to give our attention to some of the deep and intractable issues in history and to express our opinions of them. All these issues - war, peace, power, law, government, justice, rights - were philosophical matters. Never before had I seen a roomful of youngsters stay so captivated by a class and so eager to debate the questions at hand. Then, months later, I found myself reading Marcus Long's The Spirit of Philosophy, overseen by the brilliant and wholly engaging Professor Emil Fackenheim. Now the hook was fully embedded. For good or ill, I was now a philosopher for life. 


\section{VK: How did these interests develop? How might they have changed?}

JW: From 1962 to 1971, I taught graduate courses on the philosophy of logic and nonclassical logics, and established Toronto's first undergraduate course in modal logic. Virtually all my dissertation was worked out in the early stages of these courses, and several of my earlier papers were mined from it, especially those on the place of relevance in logic. By the later 1960s, I had come to the view that the conditions that define the consequence relation are seriously unreliable when used as rules of deductive inference. At this same time, the rise of pluralism in logic had caught my attention, and in 1965 I published in Dialogue my first paper on how conflicts in the non-empirical sciences are to be adjudicated ("On how to argue about entailment"). I returned to the question several years later in Paradox and Paraconsistency: Conflict Resolution in the Abstract Sciences (2003). Meanwhile, in 1969 I would publish in the Southern Journal of Philosophy the paper "Fictionality and the logic of relations" that launched my work in the philosophy of fiction, a theme to which I returned in the five years following. At this same time, C. L. Hamblin's book Fallacies (1970) had burst onto the scene, with its searing indictment of symbolic logicians for having abandoned the fallacies project that had been an integral part of logic from Aristotle until the latter $19^{\text {th }}$ century. One day in San Francisco, Douglas Walton, my former graduate student and then-assistant professor at the University of Winnipeg, agreed that we should take up Hamblin's challenge. In short order there appeared the papers that made up the so-called Woods-Walton Approach in the interval 1972-1982. Walton has remained a central figure in this sphere of interest and has enriched it with a dazzling number of important books. My own further involvements have led in a somewhat different direction, culminating in my first big work on the naturalization of logic, Errors of Reasoning: Naturalizing the Logic of Inference (2013). Soon to follow were two more monographs, each being a test case for the causal-response theory of knowledge that underlies my concluding position on the fallacies in 2013. One deals with the logico-epistemics of criminal trials (Is Legal Reasoning Irrational? An Introduction to the Epistemology of Law, 2015, second revised edition, 2018). The second returns to the logic of fiction (Truth in Fiction: Rethinking its Logic, 2018), the latter being based on my Istanbul lectures in the UNILOG 2015 Summer Institute of Logic. Next on the agenda is a causal-response logic for mathematical knowledge, with my former student and now UBC colleague Alirio Rosales.

Henry Ford is said to have said that history is just one thing after another. The genius of the production line missed a point of importance. History is several things occasioned by several others. Thanks to the Woods-Walton Approach to the fallacies, for most of the years from 1987 to 2000, enjoyed the hospitality of Frans van Eemeren and Rob Grootendorst in Amsterdam's pragma-dialectics group. One year, Hans Hansen and Larry Powers were also visiting, and many hours of instructive discussion would lead to deepening interest in Aristotle's logic, which remains a central part of my present work. Aristotle's Earlier Logic appeared with Hermes Science in Paris in 2001, and a second and much-revised edition was published in London in 2014. Shortly after the Amsterdam connection had started, Dov Gabbay organized a large working group in one of Germany's famous spas. The idea was that informal logicians and argumentation theorists might join forces with mathematical logicians who sought for realistic practical applications of 
their respective formal systems. Alas, the grand alliance wasn't achieved, but for me there were some valuable collateral benefits. One was the happy occasion to renew my acquaintance with Dov after our time together in Stanford in 1971, where, among other things, I wrote the lectures that would make up the bulk of The Logic of Fiction (1974). In due course, I would take up the Charles S. Peirce Visiting Professorship of Logic in Dov's Group on Logic and Computation at King's College London. During my twelve years there, Dov and I published the first two volumes of our omnibus work A Practical Logic of Practical Systems - Agenda Relevance (2003) and The Reach of Abduction (2005). In the first, relevance is made out to be a causal relation defined over information and knowledge-seeking information-processors. In the second, abductive inference is said to conform to what is now known as the Gabbay-Woods Schema. In subsequent writings, I've been able to show how ignorance-preserving inferences can nevertheless be knowledgeproducing. The sting of paradox vanishes when the fact is born in mind that, on the causalresponse model of knowledge, the KK-hypothesis collapses. It is perfectly possible and routinely the case that the knowledge we have of a thing is a knowledge we don't know that we have. The Gabbay-Woods involvement also gave rise to the Handbook of the History of Logic, edited in 11 volumes from 2004 to 2014, and the Handbook of the Philosophy of Science, general-edited in 16 volumes from 2006 to 2012 .

It is said that there are two rather basic ways to be a working philosopher. In one, you pick a research topic and work it to death for the next fifty or so years. In the other, you follow your nose and wait to see what happens, wherever it takes you. Some of philosophy's great achievements come about in the first way. But rather more, I think, come about in the second. Sometimes what we've been waiting for turns out to be a very large and versatile - indeed spread-about-body of work that chances to have danced to a quite particular idea over those same fifty years or so.

As it happens, in all my work, including that on Aristotle's logic and the philosophy of the modalities, a certain theme recurs. It reflects my dissatisfaction with present-day inclinations to elucidate matters of philosophical importance by making formal models of them in highly idealized mathematical systems. The objection is attended on the positive side by the hope that great improvements lie in the wherewithal of naturalized logics to pay serious and respectful heed to the lived realities of cognitive life in a species which, against all odds imposed by the brute facts of unfriendly nature, has not only survived but also cognitively prospered, and from time to time built great civilizations.

VK: Could you say a bit more about how you see logic's present position and how would you judge its future prospects?

JW: In the second edition of the first Critique, Kant raised the curtain on the state that logic would be in in the $19^{\text {th }}$ century. He observed that Aristotle's logic could not be faulted for the strides it had made with deduction, and he added that, by its very structure, it could go no further. Kant was calling for a logic that could accommodate the plethora of new deductive realities of modern-day science. 
It is widely agreed that logic's next great step was Frege's Grundgesetze $(1893,1903)$, in which every truth of arithmetic (vol. 1) and of upper division mathematics (vol. 2 and the never-tobe published vol. 3) could be proved to repose in the demonstrative closure of Grundgesetze's primitive truths. This reduction came to be known as logicism, according to which all of mathematics would absorb the certainties that inhere in pure logic. The Grundgesetze advanced a second-order functional calculus, but in due course, between 1903 and »1930, philosophers came to favour first-order versions of something close to the Fregean paradigm. The newer logic would return set theory to its proper place in mathematics, thus freeing itself from the necessity and the means to support logicism.

It is now ninety-one years later and, following its nearly century-long philosophical dominance, logic finds itself in somewhat the place in which Kant found the old logic in 1787. It is time for modern-day logic to up its game. In this respect, Aristotle's demonstrative logic had an advantage not present in Frege's or our own. Aristotle's logics were fashioned in response to (but not in these words) the threefold nature of consequence-manifestation. At the first level is consequence-having (or entailment) which obtains, or not, in logical space, independently of any human involvement. Next comes consequence-spotting (as in conditional proof, for example). Spottings occur in psychological space and require the participation of human agents. Finally comes consequence-drawing (or inference, belief-update revision), which occurs in the inferential subspace of psychological space. It has been known since the late 1960s that the conditions on consequence-having or entailment fail the lived realities of cognitive life when re-issued as rules of truth-preserving inference. All the same, philosophers have paid little heed to this setback, save for evasive measures to spare it the embarrassment of not being true to human life. The evasion would be predicated on the utter fiction that humans reason at their best-possible by approximating to the inferential behaviour of some supposed ideally rational agent.

To a large extent, a tenable logic of human inference at its humanly possible best will require a vigorous, knowledgeable, selective, circumspect and self-critical partnership with all the cognitive sciences. This alliance would bring forth a naturalized logic of inference. This, I predict, is one of logic's next frontiers. So, too, perhaps, will be the enlargement of the recent reapproachment between logicians and legal theorists.

It is also time to reassess the importance of first-order logic for computer science, a matter which neither Aristotle nor Frege could have countenanced. There is a still-minority opinion, which I share, that given the burdens placed on the foundational security of computer science, first-order logic is no longer capable of meeting this need. What is required, I believe, is a strongly typed higher order logic in which, among other things, there is a high and orderly tolerance of pervasive inconsistency, managed without impairment of the classical consequence relation. This, I predict, will be another growth area for logic. 
VK: Can you give us some idea of the younger logicians who have come to your attention?

JW: Among the younger logicians, I have the pleasure of knowing Daniele Chiffi (Milan Polytech), Matthieu Fontaine (Lisbon), Cristina Barés-Gomez (Sevilla), Selene Arfini (Pavia), Manuel Gustavo Isaac (Barcelona and St. Andrews), Gillman Payette (Lethbridge), David Gilbert (UBC), Martín Castro-Manzano (Autonomous University of Nayarit), and among the emerging newcomers Travis La Croix (UC Irvine), Frank Hong (Southern California) Katharina Stevens (Lethbridge), and Basak Kurtuldu (Istanbul).

VK: Thank you, John Woods, for such interesting responses.

JW: Thank you, Professor Kamer for such inviting questions and for your indulgence of such lengthy replies! 